\title{
Synthesis of Alternating Copolymalonamides by Ring-Opening Polyaddition Reaction of Bismalonimide with Diamines
}

\author{
Yoshio Imai and Hiroshi Hirukawa \\ Department of Polymer Chemistry, Faculty of Engineering, \\ Yamagata University, Yonezawa, Yamagata, Japan.
}

(Received April 17, 1972)

\begin{abstract}
A new $N, N^{\prime}$-disubstituted bismalonimide was synthesized by the cycloaddition of methylenebis(4-phenylisocyanate) with pentamethyleneketene. Ringopening polyaddition reaction of the bismalonimide with aliphatic diamines was carried out in $N$-methyl-2-pyrrolidone to give a new class of alternating copolymalonamides having inherent viscosity of $0.5-1.0$ in quantitative yield. The solution polymerization was almost completed at room temperature within $24 \mathrm{hr}$, or at $80^{\circ} \mathrm{C}$ within an hour. In methyl ethyl ketone, precipitation of polymer occurred to yield the polymer with rather lower inherent viscosity. The alternating copolymalonamides were amorphous, and showed melt temperature in the range of $150-200^{\circ} \mathrm{C}$.
\end{abstract}

KEY WORDS Alternating Copolymalonamides / Ring-opening Polyaddition Reaction / Bismalonimide / Diamines / $N$-Methyl-2-pyrrolidone / Infrared Spectra / Solubility / X-Ray Diffraction Diagrams / Thermal Behavior /

Ring-opening polyaddition reaction of $N, N^{\prime}$ disubstituted bisimides with diamines has recently received considerable attention in the preparation of ordered copolyamides. Typical examples are the regularly alternating mixed polysuccinamides and polyglutaramides obtained from the corresponding five-membered and sixmembered bisimides, respectively, by both melt ${ }^{1-3}$ and solution ${ }^{2}$ polymerization techniques. In the present paper the synthesis is described of a new and more reactive four-membered bisimide, which is subjected to the ring-opening polyaddition reaction with diamines to form highmolecular-weight alternating copolymalonamides under mild ambient conditions.

\section{RESULTS AND DISCUSSION}

\section{Synthesis of Bismalonimide}

Although several methods are known for the preparation of monomalonimides, ${ }^{4}$ the only bismalonimide described in the literature was obtained by a ring-closure method. ${ }^{5}$ In this paper the successful synthesis discussed of $N, N^{\prime}$-methylenediphenylenebis(2, 2-pentamethylenemalonimide) (BMI) by the cycloaddition reaction of methylenebis(4-phenyl isocyanate) (MDI) and pentamethyleneketene in refluxing toluene by modifying the method described by Poshkus and Herweh. ${ }^{6}$ The yield of purified BMI was $25 \%$. During the course of this investigation, it was reported independently by Martin, et al., ${ }^{7}$ that several bismalonimides were prepared by a method similar to the one mentioned here.

2
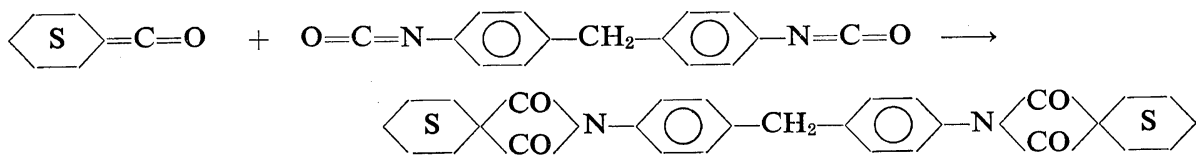

BMI showed infrared (IR) absorption bands at $1855 \mathrm{~cm}^{-1}$ and $1730 \mathrm{~cm}^{-1}$ characteristic of a four-

membered imide ring ${ }^{5}$, as given in Figure 1. Elemental analysis of BMI was also in close 


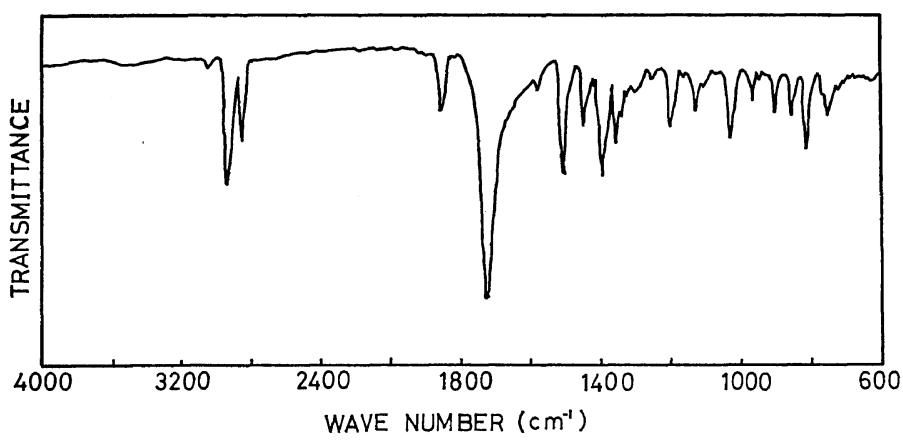

Figure 1. Infrared spectrum of the monomer $\mathrm{BMI}$ on a $\mathrm{KBr}$ pellet.

agreement with the expected structure.

\section{Model Reaction}

of BMI was attempted with typical aliphatic and aromatic amines.

Prior to polymer synthesis, the model reaction

2

$2 \mathrm{R}-\mathrm{NH}_{2}+\langle\overline{\mathrm{S}}\rangle\langle\mathrm{CO}$<smiles></smiles>

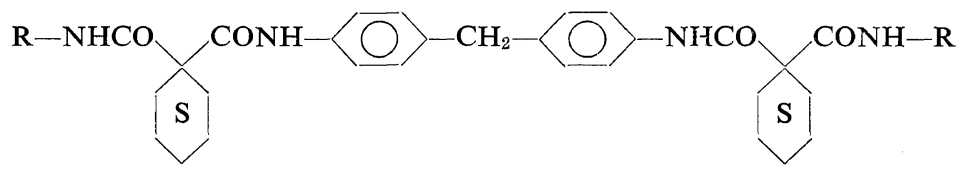

$\mathrm{R}, n-\mathrm{C}_{4} \mathrm{H}_{9}-(\mathbf{I})$;

$n$-Butylamine reacted readily with BMI in 78-\% yield in tetrahydrofuran (THF) at room temperature to give the ring-opening adduct $\mathbf{I}$, which was identified by elemental analysis. IR spectrum of the adduct $\mathbf{I}$ is shown in Figure 2. On the other hand, aniline was less reactive

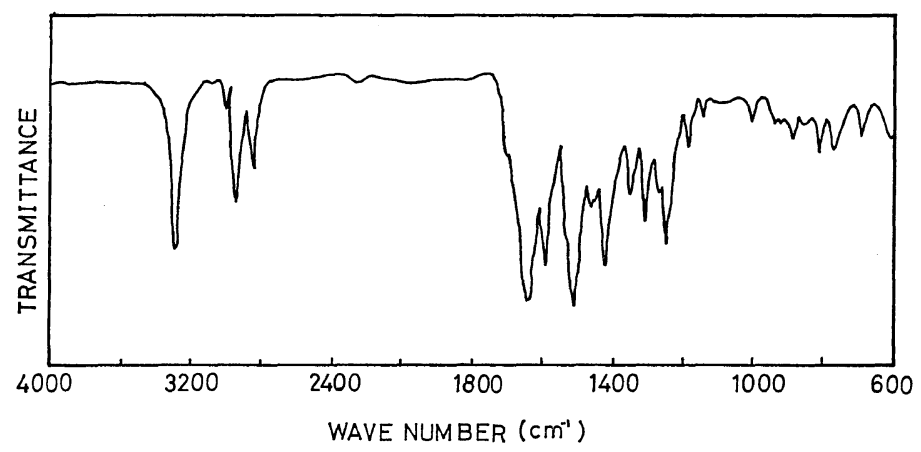

Figure 2. Infrared spectrum of the ring-opening adduct $\mathrm{I}$ on a $\mathrm{KBr}$ pellet.

than $n$-butylamine toward BMI, and the reaction required an elevated temperature. The reaction in $N$-methyl-2-pyrrolidone (NMP) at $150^{\circ} \mathrm{C}$ yielded a trace amount of the adduct II, which was determined by elemental analysis, and that in refluxing toluene in the presence of $p$-toluenesulfonic acid gave the product II in 11-\% yield. IR spectrum of the adduct II was essentially identical with that of the adduct $\mathbf{I}$. 


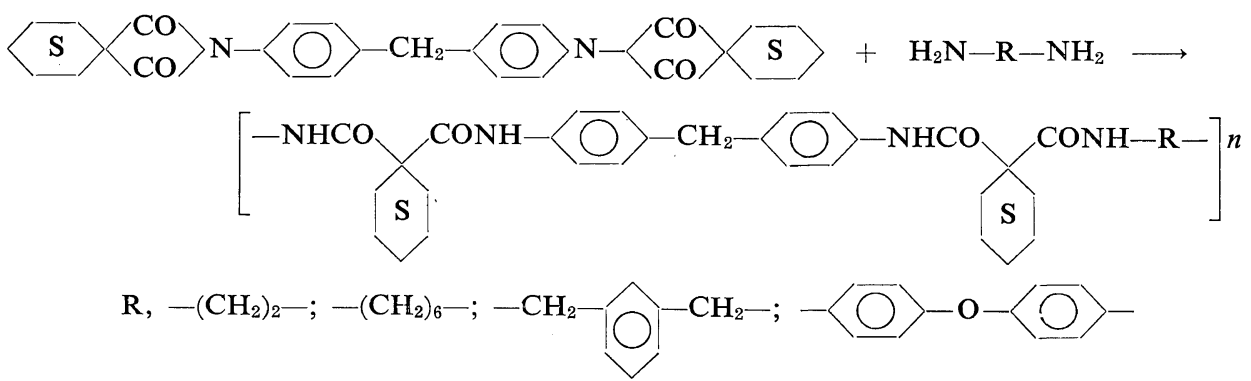

The polymerization was carried out in NMP and methyl ethyl ketone (MEK) at ambient and elevated temperatures. The results are listed in

Table I. Ring-opening polyaddition reaction of BMI with various diamines in NMPa

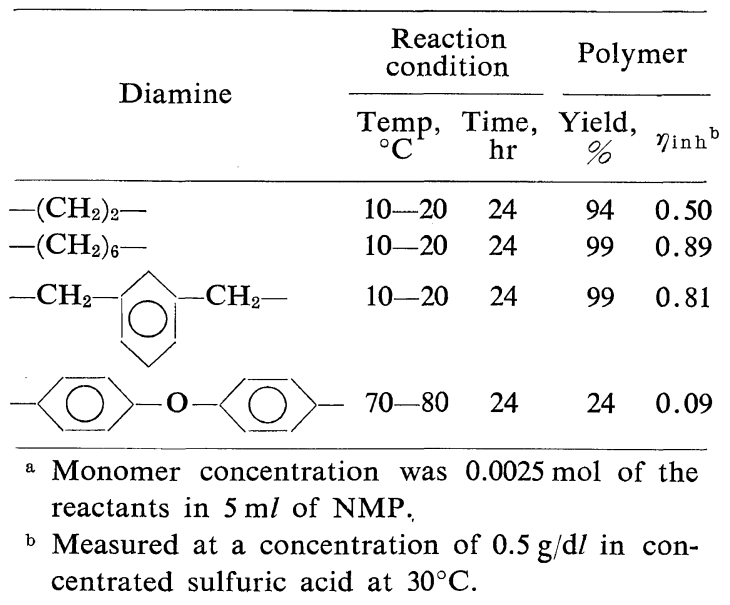

Tables I and II.

Figures 3 and 4 show the rate of polymerization of BMI with hexamethylenediamine (HMDA) in NMP in terms of solution viscosity of polymers. The reaction proceeded fairly slowly in solution at room temperature and was

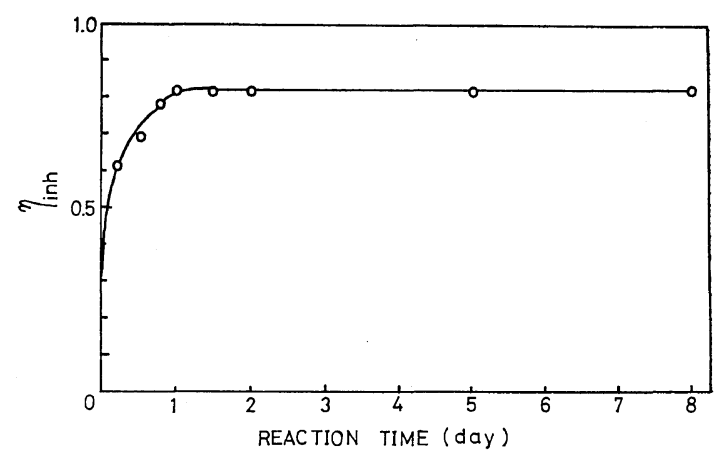

Figure 3. Polymerization of BMI with HMDA in NMP at room temperature.

Table II. Ring-opening polyaddition reaction of BMI with hexamethylenediamine under various reaction conditions

\begin{tabular}{|c|c|c|c|c|c|}
\hline \multirow{2}{*}{ Solvent ${ }^{a}$} & \multirow{2}{*}{ Additive, ${ }^{\mathrm{b}} \mathrm{g}$} & \multicolumn{2}{|c|}{ Reaction condition } & \multicolumn{2}{|c|}{ Polymer } \\
\hline & & Temp, ${ }^{\circ} \mathrm{C}$ & Time, hr & Yield, $\%$ & $\eta_{\mathrm{inh}}{ }^{\mathrm{c}}$ \\
\hline NMP & None & $10-20$ & 24 & 99 & 0.89 \\
\hline " & None & $70-80$ & 24 & 99 & 0.82 \\
\hline$" \prime$ & Water, 0.01 & $10-20$ & 24 & 96 & 0.63 \\
\hline " & TED, $\quad 0.03$ & $10-20$ & 24 & 99 & 0.80 \\
\hline MEK & None & $70-80$ & 6 & 99 & 0.33 \\
\hline "I & Water, 0.01 & $70-80$ & 6 & 99 & 0.36 \\
\hline$" \prime$ & Water, 1.0 & $70-80$ & 6 & 99 & 0.48 \\
\hline$\prime \prime$ & TED, $\quad 0.03$ & $70-80$ & 6 & 97 & 0.30 \\
\hline
\end{tabular}

a Monomer concentration was $0.0025 \mathrm{~mol}$ of the reactants in $5 \mathrm{~m} l$ of NMP or in $10 \mathrm{~m} l$ of $\mathrm{MEK}$.

b TED denotes triethylenediamine.

c Measured at a concentration of $0.5 \mathrm{~g} / \mathrm{d} l$ in concentrated sulfuric acid at $30^{\circ} \mathrm{C}$. 


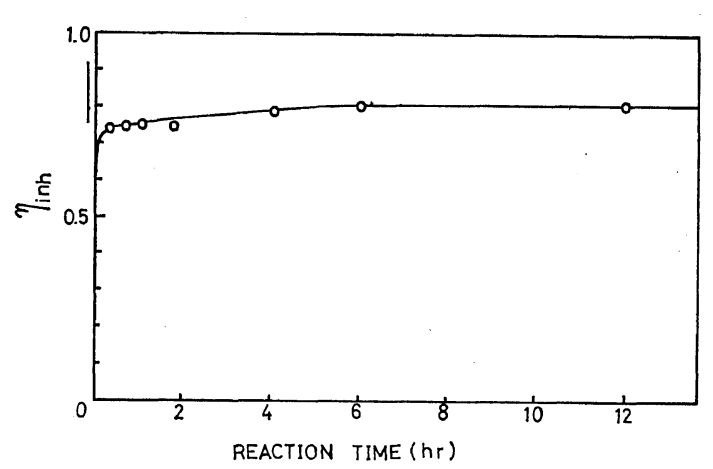

Figure 4. Polymerization of BMI with HMDA in NMP at $80^{\circ} \mathrm{C}$.

almost completed within a day to form the alternating copolymalonamide having a high molecular weight, whereas the reaction at $80^{\circ} \mathrm{C}$ reached essential completion within an hour. The reaction temperature had no effect on the attained molecular weight of the polymer.

As shown in Table I, the reaction of BMI with aliphatic diamines such as ethylenediamine, hexamethylenediamine, and $m$-xylylenediamine, quite readily gave alternating copolymalonamides having a high inherent viscosity in the range of 0.5-1.0. However, the reaction with bis(4aminophenyl)ether took place much more slowly than that of aliphatic diamines as can be anticipated from the result of the model reaction. Neither the yield nor the molecular weight of the copolymalonamide was satisfactory.

The polymerization was greatly influenced by the solvent (Table II). The reaction in NMP proceeded in a homogeneous phase to give a high-molecular-weight polymer, as discussed above. However, use of MEK as a solvent reduced the inherent viscosity to almost one half, although the yield of the polymer was nearly quantitative. The reason may be ascribed to the heterogeneous reaction phase, since copolymalonamide was gradually precipitated out of the solution in MEK during the course of the polymerization.

The addition of water to the reaction medium, particulary to MEK, seemed to be effective for increasing the molecular weight of the polymer to some extent. The positive effect of the binary system of MEK and water has been found previously in the preparation of a high-molecularweight polyamide-acid. ${ }^{8}$ Triethylenediamine as a catalyst was ineffective in this ring-opening polyaddition reaction.

\section{Properties of Alternating Copolymalonamides}

Polymers obtained here were identified as polyamides from their infrared spectra and elemental analyses. IR spectrum of the typical polymer is given in Figure 5. The characteristic absorption bands of malonimide at $1855 \mathrm{~cm}^{-1}$ and $1730 \mathrm{~cm}^{-1}$ disappeared, while the spectrum showed the characteristic of secondary amide at $3340,1650,1520$, and $1310 \mathrm{~cm}^{-1}$. The spectrum of the polymer was very similar to that of the ring-opening adduct shown in Figure 2.

These alternating copolymalonamides were soluble in $N, N$-dimethylacetamide, NMP, $m$ cresol, and concentrated sulfuric acid, and were partially soluble or swollen in formic acid and pyridine. They were insoluble in common organic solvents. Transparent and tough films were obtained by casting from dimethylacetamide

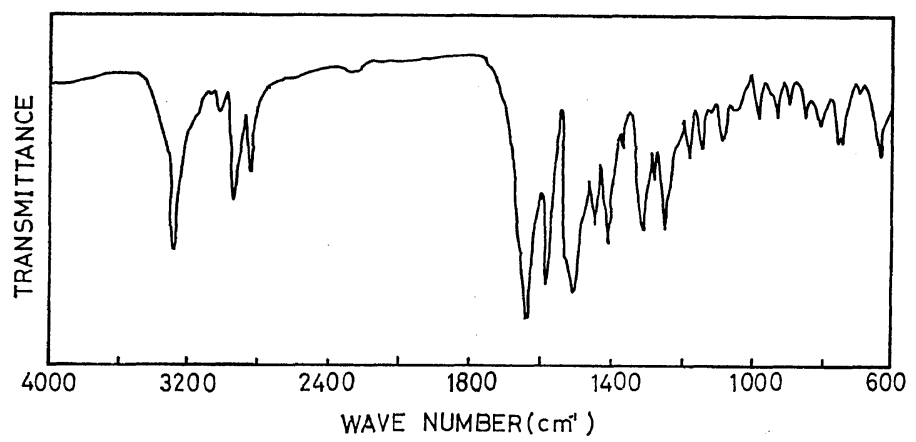

Figure 5. Infrared spectrum of a film of the polymer obtained from BMI and HMDA. 


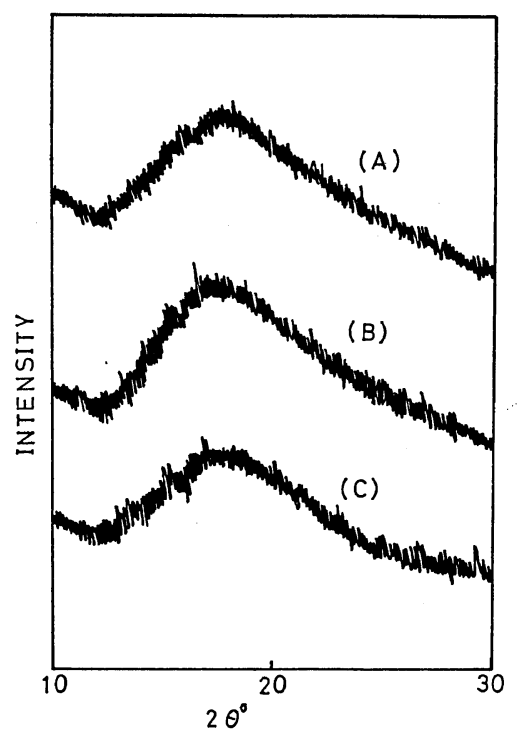

Figure 6. X-Ray diffraction diagrams of the polymers obtained from various diamines and BMI: (A) from HMDA; (B) from $m$-xylylenediamine; (C) from ethylenediamine.

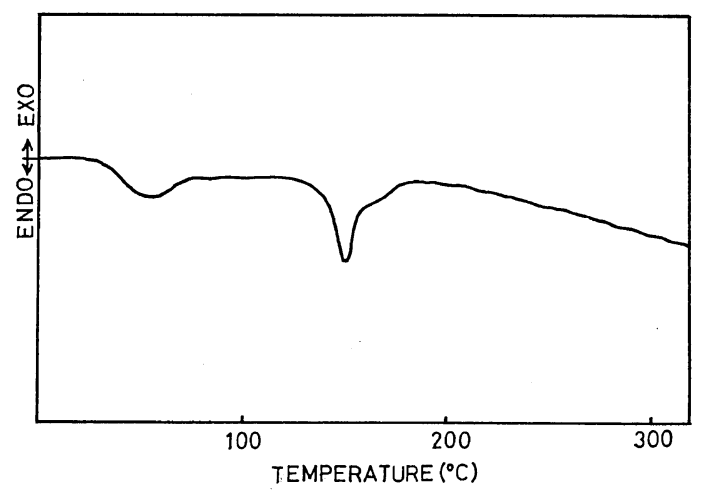

Figure 7. DTA curve of the polymer obtained from $\mathrm{BMI}$ and HMDA in $\mathrm{N}_{2}$ at a heating rate of $15^{\circ} \mathrm{C} / \mathrm{min}$.

solution.

X-Ray diffraction diagrams of films of the polymers, shown in Figure 6, were obtained by the use of nickel-filtered $\mathrm{CuK} \alpha$ radiation. The diagrams indicate that the alternating copolymalonamides were all amorphous.

Melting points and decomposition temperatures of the polymers were determined by means of differential thermal analysis (DTA) and thermo-

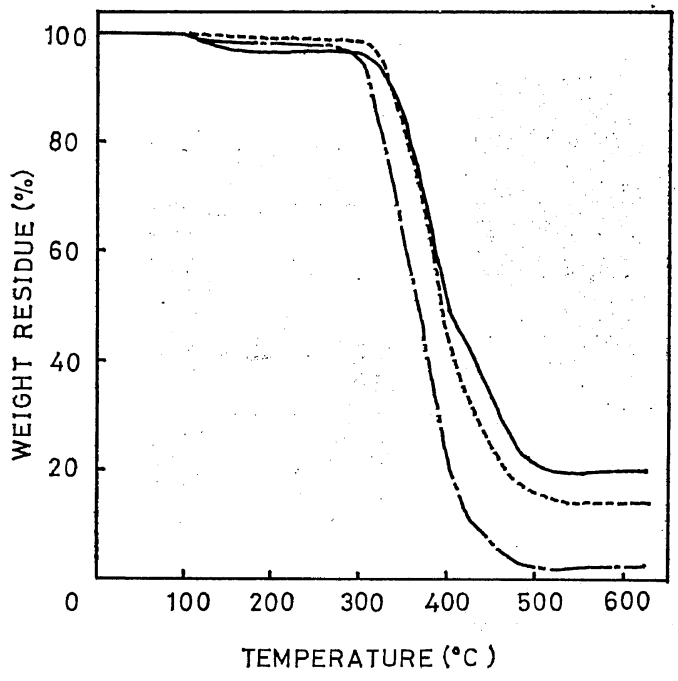

Figure 8. TGA curves of the polymers obtained from various diamines and $\mathrm{BMI}$ in $\mathrm{N}_{2}$ at a heating rate of $5^{\circ} \mathrm{C} / \mathrm{min}:-\cdots-$, from HMDA; from ethylenediamine; ------, from $m$-xylylenediamine.

Table III. Thermal behavior data of alternating copolymalonamides from BMI and diamines

\begin{tabular}{lcc}
\hline Diamine & $\begin{array}{c}\mathrm{PMT}^{\circ} \mathrm{C}, \\
-\left(\mathrm{CH}_{2}\right)_{2}-\end{array}$ & $\begin{array}{c}\text { Decomposition } \\
\text { temperature, }{ }^{\circ}{ }^{\circ} \mathrm{C}\end{array}$ \\
$-\left(\mathrm{CH}_{2}\right)_{6}-$ & 175 & 335 \\
$-\mathrm{CH}_{2}-\mathrm{CH}_{2}-$ & 185 & 310 \\
& & 330 \\
\hline
\end{tabular}

a Polymer-melt temperature determined by DTA in $\mathrm{N}_{2}$ (heating rate, $15^{\circ} \mathrm{C} / \mathrm{min}$ ).

b Decomposition temperature observed by TGA in $\mathrm{N}_{2}$ (heating rate, $5^{\circ} \mathrm{C} / \mathrm{min}$ ). The temperature given is that at which weight loss of a polymer reaches a value of $10 \%$ based on the original weight.

gravimetric analysis (TGA), respectively. The curves are given in Figures 7 and 8 , and the thermal behavior data are summarized in Table III. The alternating copolymalonamides obtained here show polymer-melt temperature in the range of $150-200^{\circ} \mathrm{C}$, and a breakdown at a temperature above $300^{\circ} \mathrm{C}$ in a nitrogen atmosphere.

The low polymer-melt temperature is presumed to be lack of hydrogen bonding between amide 


\section{Y. Imai and H. Hirukawa}

linkages by steric hindrance of bulky cyclohexane rings along the polymer chain.

\section{EXPERIMENTAL}

\section{Materials}

Cyclohexanecarboxylic acid, $n$-butylamine, aniline, ethylenediamine, and hexamethylenediamine, were all reagent-grade materials, and were used without any particular purification. Methylenebis(4-phenyl isocyanate) (provided by Nippon Polyurethane Industries Co.) and $m$ xylylenediamine (provided by Showa Denko Co.) were distilled under reduced pressure before use. Bis(4-aminophenyl) ether, provided by Sumitomo Chemical Co., was purified by recrystallization from tetrahydrofuran. Toluene, tetrahydrofuran, and methyl ethyl ketone (MEK) were obtained commercially in reagent grade and were used without any treatment except storage over molecular sieves 4A. $N$-methyl-2-pyrrolidone (NMP, provided by Mitsubishi Chemical Industries Ltd.) was purified by vacuum distillation and stored over molecular sieves4A. Other materials were all obtained commercially.

\section{Synthesis of Bismalonimide}

Cyclohexanecarbonyl chloride was prepared in $84-\%$ yield by a conventional method from the corresponding carboxylic acid and excess of thionyl chloride, bp $78^{\circ} \mathrm{C}(22 \mathrm{~mm})\left[1\right.$ it. ${ }^{9}$ bp $67^{\circ} \mathrm{C}$ $(14 \mathrm{~mm})]$.

Bismalonimide was synthesized principally by the extension of the method described by Poshkus and Herweh, ${ }^{6}$ by the cycloaddition reaction of pentamethyleneketene derived from cyclohexanecarbonyl chloride and methylenebis-(4-phenyl isocyanate). Typical synthesis is shown below.

Into a stirred solution of $30 \mathrm{~g}(0.2 \mathrm{~mol})$ of cyclohexanecarbonyl chloride in $100 \mathrm{ml}$ of toluene, $25 \mathrm{~g}(0.24 \mathrm{~mol})$ of triethylamine was added within $20 \mathrm{~min}$ at room temperature. After stirring for $1 \mathrm{hr}$, the reaction mixture was then filtered. The filter cake was identified as triethylamine hydrochloride. The filtrate containing mainly pentamethyleneketene was added to a solution of $15 \mathrm{~g}(0.06 \mathrm{~mol})$ of methylenebis(4-phenyl isocyanate) in $100 \mathrm{~m} l$ of toluene. The mixture was refluxed for $48 \mathrm{hr}$ with stirring. The cooled, turbid reaction mixture was again filtered, and the second filter cake was also identified as triethylamine hydrochloride. The filtrate was evaporated followed by washing the residue with cyclohexane. Repeated recrystallization from ethanol gave white leaflets melting at 203.5$204^{\circ} \mathrm{C}$. The yield of pure $N, N^{\prime}$-methylenediphenylenebis (2, 2- pentamethylenemalonimide) (BMI) was $7.2 \mathrm{~g}$ (25\% based on the diisocyanate).

$$
\begin{aligned}
& \text { Anal. Calcd for } \mathrm{C}_{29} \mathrm{H}_{30} \mathrm{~N}_{2} \mathrm{O}_{4} \text { : } \\
& \text { C, 74.01; } \mathrm{H}, 6.44 ; \mathrm{N}, 5.95 . \\
& \text { Found: C, 74.53; H, 6.63; N, 5.80. }
\end{aligned}
$$

\section{Model Reaction of BMI with n-Butylamine}

A solution of $1.18 \mathrm{~g}(0.0025 \mathrm{~mol})$ of BMI and $0.37 \mathrm{~g}(0.005 \mathrm{~mol})$ of $n$-butylamine in $12 \mathrm{ml}$ of tetrahydrofuran was stirred at room temperature for $12 \mathrm{hr}$. The white precipitate formed was collected by filtration, washed with the fresh solvent, and dried. The ring-opening adduct $\mathbf{I}$, melting at $223-224^{\circ} \mathrm{C}$, weighed $1.21 \mathrm{~g}(78 \%)$.

\section{Anal. Calcd for $\mathrm{C}_{37} \mathrm{H}_{52} \mathrm{~N}_{4} \mathrm{O}_{4}$ :}

C, 72.02; H, 8.51; N, 9.08.

Found: C, 73.19; H, 8.59; N, 9.04.

\section{Model Reaction of BMI with Aniline}

A solution of $2.35 \mathrm{~g}(0.005 \mathrm{~mol})$ of BMI, 1.02 $\mathrm{g}(0.011 \mathrm{~mol})$ of aniline, and $0.02 \mathrm{~g}$ of $p$-toluenesulfonic acid in $10 \mathrm{~m} l$ of toluene was refluxed for $20 \mathrm{hr}$ with stirring. The white solid precipitated was filtered, and recrystallized from benzene. The ring-opening adduct II was obtained as white needles and melted at $274^{\circ} \mathrm{C}$. The yield of the pure product was $0.38 \mathrm{~g}(11 \%)$.

\section{Aral. Calcd for $\mathrm{C}_{41} \mathrm{H}_{44} \mathrm{~N}_{4} \mathrm{O}_{4}$ :} $\mathrm{C}, 74.96 ; \mathrm{H}, 6.77 ; \mathrm{N}, 8.53$. Found: C, 73.82; H, 6.33; N, 8.65.

\section{Solution Polymerization in NMP}

Two typical examples of polymerization procedure are as follows.

A solution of $1.18 \mathrm{~g}(0.0025 \mathrm{~mol})$ of BMI and $0.29 \mathrm{~g}(0.0025 \mathrm{~mol})$ of hexamethylenediamine in $5 \mathrm{~m} l$ of NMP was reacted with stirring at room temperature for $24 \mathrm{hr}$. The slightly viscous soution formed was poured into $200 \mathrm{~m} l$ of acetone. The resulting polymer was filtered, followed by washing with boiling acetone, and drying at $60^{\circ} \mathrm{C}$ under vacuum. The yield was $1.46 \mathrm{~g}$ (99\%). Inherent viscosity of the polymer in concentrated sulfuric acid was 0.89 , measured at a concentration of $0.5 \mathrm{~g} / \mathrm{d} l$ at $30^{\circ} \mathrm{C}$. 
Anal. Calcd for $\left(\mathrm{C}_{35} \mathrm{H}_{40} \mathrm{~N}_{4} \mathrm{O}_{4}\right)_{n}$ : $\mathrm{C}, 72.38 ; \mathrm{H}, 6.96 ; \mathrm{N}, 9.65$.

Found: C, 70.92; H, 8.30; N, 9.44.

In a similar manner as above, BMI and $m$ xylylenediamine as diamine component gave the polymer having inherent viscosity of 0.81 in quantitative yield.

Anal. Calcd for $\left(\mathrm{C}_{37} \mathrm{H}_{42} \mathrm{~N}_{4} \mathrm{O}_{4}\right)_{n}$ : $\mathrm{C}, 73.22 ; \mathrm{H}, 6.99 ; \mathrm{N}, 9.23$.

Found: $\mathrm{C}, 72.51 ; \mathrm{H}, 7.72 ; \mathrm{N}, 9.20$.

\section{Solution Polymerization in MEK}

A typical preparation is given below.

Into a hot solution of $1.18 \mathrm{~g}$ of BMI in $10 \mathrm{~m} l$ of MEK was added $0.29 \mathrm{~g}$ of hexamethylenediamine all at once, and the resulting solution was refluxed at $70-80^{\circ} \mathrm{C}$. The polymer was precipitated out of the solution as the reaction proceeded. After refluxing for $6 \mathrm{hr}$, the separated polymer was collected, washed with acetone, and dried at $60^{\circ} \mathrm{C}$ under vacuum. The yield was $1.46 \mathrm{~g}$, and the inherent viscosity was 0.33 .

\section{Measurements}

The infrared spectra were obtained on a Japan Spectroscopic Co. diffraction grating infrared spectrophotometer, Model IRA-1.

The X-ray diffraction diagrams were obtained in a Rigaku Denki X-ray diffractometer, Model RU-3H.

Thermal-behavior data were obtained by use of a Simazu micro-differential thermal analyzer, Model DT-20B, and its micro-thermogravimetric analyzer, Model TGC-20 and TG-20.

Acknowledgments. The authors are grateful to Nippon Polyurethane Industries Co., Showa Denko Co., Sumitomo Chemical Co., and Mitsubishi Chemical Industries Ltd., for kindly supplying samples of the monomers and the solvent. The authors are also indebted to Assistant Professor Shogo Niino and his coworkers for the elemental analyses and to Assistant Professor Kazuo Matsuda and his group for the X-ray analyses.

\section{REFERENCES}

1. T. Kagiya, M. Izu, T. Matsuda, and K. Fukui, J. Polym. Sci., Part A-1, 5, 15 (1967).

2. T. V. Sheremeteva, G. N. Larina, M. G. Zhenevskaya, and V. A. Gusinskaya, ibid., Part C, 16, 1631 (1967).

3. J. Sambeth and F. Grundschober, Preprints, International Symposium on Macromolecular Chemistry, Tokyo-Kyoto, 1966, p I-269.

4. S. A. Ballard and D. S. Melstrom, "Heterocyclic Compounds," Vol. I, R. C. Elderfield, Ed., John Wiley and Sons, Inc., New York, N. Y., 1950, p 111.

5. A. Ebnöther, E. Jucker, E. Rissi, J. Rutschmann, E. Schreier, R. Steiner, R. Süess, and A. Vogel, Helv. Chim. Acta, 42, 918 (1959).

6. A. C. Poshkus and J. E. Herweh, J. Org. Chem., 30, 2466 (1965).

7. J. C. Martin, R. D. Burpitt, P. G. Gott, M. Harris, and R. H. Meen, ibid., 36, 2205 (1971).

8. Y. Imai and H. Uchiyama, J. Polymer. Sci., Part B, 8, 559 (1970); Kobunshi kagaku (Chem. High Polymers) 28, 73 (1971).

9. W. F. Charnicki and J. B. Data, J. Amer. Pharm. Assoc., 45, 65 (1956); Chem. Abstr., 50, 13834 b (1956). 